\title{
GAMBARAN PENGETAHUAN DAN SIKAP PENYEBAB RENDAHNYA KUNJUNGAN LANSIA DI POSYANDU LANSIA SALO TIMUR
}

\author{
Rizki Rahmawati Lestari \\ Prodi S1 Kesehatan Masyarakat, Fakultas Ilmu Kesehatan \\ Universitas Pahlawan Tuanku Tambusai \\ rizkirahmawati48@gmail.com
}

\begin{abstract}
The Elderly Posyandu is a place for the elderly to get health services through promotive and preventive efforts without neglecting curative and rehabilitative efforts. The purpose of this study was to determine the Description of Knowledge and Attitudes that Caused the Low Visits of the Elderly in the Elderly Posyandu in East Salo. In this study, the researcher only wanted to know the description of the knowledge and attitudes of the elderly towards the Posyandu for the elderly. This research method is carried out with descriptive design using primary data. The population of the research sample is the elderly who are under the guidance of the Elderly Posyandu in East Salo Village, and the sample is 77 people. The research instrument is using a questionnaire. Data analysis using Univariate method. The results of this study were the elderly had a good level of knowledge, namely as many as 2 people (2.6\%), the elderly who had a sufficient level of knowledge were as many as 12 people $(15,6 \%)$. And the elderly who have a low level of knowledge are 63 people (81.8\%). And the results of the research on attitudes are negative attitudes towards the Elderly Posyandu as many as 45 people (58.4\%), and having a positive attitude towards the Elderly Posyandu as many as 32 people (41.6\%). The conclusion of this study, the elderly in East Salo Village have less knowledge about the Elderly Posyandu and have a negative attitude towards the Elderly Posyandu.
\end{abstract}

Keywords : Posyandu elderly, Knowledge, Attitudes

\begin{abstract}
ABSTRAK
Posyandu Lansia adalah suatu tempat bagi Lansia untuk mendapatkan pelayanan kesehatan melalui upaya promotif, preventif tanpa mengabaikan upaya kuratif dan rehabilitatif. Di desa Salo Timur terdapat 328 jiwa lansia, namun hanya 30 orang yang aktif untuk mengikuti kegiatan posyandu Lansia. Tujuan penelitian ini adalah untuk mengetahui Gambaran Pengetahuan dan Sikap Penyebab Rendahnya Kunjungan Lansia di Posyandu Lansia Salo Timur. Dalam penelitian ini peneliti ingin mengetahui gambaran pengetahuan dan sikap Lansia terhadap Posyandu Lansia. Metode penelitian ini dilakukan dengan desain Deskriptif dengan menggunakan data primer. Populasi sampel penelitian adalah Lansia yang ada dibawah binaan Posyandu Lansia Desa Salo Timur, dan sampel berjumlah 77 orang. Instrumen penelitian dengan menggunakan angket. Analisa data dengan cara Univariat. Hasil penelitian ini adalah responden mempunyai tingkat pengetahuan baik yaitu sebanyak 2 orang $(2,6 \%)$, responden yang mempunyai tingkat pengetahuan cukup yaitu sebanyak 12 orang $(15,6 \%)$. Responden yang mempunyai tingkat pengetahuan kurang sebanyak 63 orang $(81,8 \%)$. Sementara hasil penelitian tentang sikap yaitu sikap Negatif terhadap Posyandu Lansia yaitu sebanyak 45 orang $(58,4 \%)$, dan mempunyai sikap positif terhadap Posyandu Lansia yaitu sebanyak 32 orang $(41,6 \%)$. Kesimpulan penelitian ini, Lansia di Desa Salo Timur memiliki pengetahuan yang kurang tentang Posyandu Lansia dan mempunyai sikap yang negatif terhadap Posyandu Lansia.
\end{abstract}

Kata Kunci : Posyandu Lansia, Pengetahuan, Sikap

\section{PENDAHULUAN}

Pembangunan kesehatan menuju masyarakat sehat 2025 bertujuan untuk meningkatkan kesadaran, kemauan, dan kemampuan hidup sehat bagi setiap jiwa agar terwujud derajat kesehatan yang optimal. Hal itu menyebabkan terjadinya 
pergeseran dari pelayanan medis menjadi pemeliharaan kesehatan yang lebih menonjolkan aspek preventif dan promotif disamping upaya kuratif dan rehabilitatif yang ada (Depkes. RI, 2015).

Salah satu hasil pembangunan kesehatan di Indonesia adalah meningkatnya harapan hidup. Dilihat dari sisi ini pembangunan kesehatan di Indonesia sudah cukup berhasil, karena angka harapan hidup bangsa kita telah meningkat secara bermakna. Namun disisi lain dengan meningkatnya angka harapan hidup ini membawa beban bagi masyarakat, karena populasi penduduk usia lanjut (Lansia) meningkat dan bertambah cenderung lebih cepat (Nugroho, 2006).

Direktur Jenderal Bina Kesehatan Masyarakat Dr Sri Astuti Suparmanto,MSc (PH) pada seminar sehari dalam memperingati Hari Lanjut Usia Nasional (HLUN), dikantor DepKes Indonesia menyatakan pemerintah telah merumuskan kebijakan, program dan kegiatan bagi para Lansia. Tujuan program usila adalah untuk meningkatkan derajat kesehatan lanjut usia agar tetap sehat, mandiri dan berdaya guna sehingga tidak menjadi beban bagi dirinya sendiri, keluarga maupun masyarakat (DepKes RI, 2015).

Tahun 2016 penduduk usia lanjut diseluruh dunia diperkirakan sebanyak 426 juta atau sekitar 6,8 \%. Jumlah ini akan meningkat hampir dua kali lipat pada tahun 2025, yaitu menjadi sekitar 828 juta jiwa atau sekitar 9,7 \% dari total penduduk dunia dengan usia rata-rata 60 tahun (Nugroho, 2017). Di negara maju seperti Amerika Serikat pertumbuhan lansia melebihi pertumbuhan non Lansia setiap tahunnya sejak tahun 2015. Persentase warga Amerika yang berusia 65 tahun ke atas telah meningkat 3 kali lipat $(4,1 \%$ pada tahun 2015 sampai $12,8 \%$ pada tahun 2018), dan jumlahnya telah meningkat hampir 11 kali lipat (dari 3,1 juta sampai 33,9 juta) (Anderson, 2019).

Di Indonesia jumlah penduduk usia lanjut tahun 2018 adalah 11,3 juta jiwa $(6,4$
$\%$ meningkat menjadi 15,3 juta $(7,4 \%)$ pada tahun 2019 dan pada tahun 2015-2020 diperkirakan akan sama dengan jumlah anak Balita yaitu sekitar 19 juta jiwa atau $8,5 \%$ dari seluruh jumlah penduduk (Depkes, 2015). Di Propinsi Riau pada tahun 2018 terdapat 642.031 jiwa lanjut usia. Di Kabupaten Kampar terdapat 41.719 orang usia lanjut, namun hanya 7.820 jiwa mendapatkan pelayanan kesehatan (DinKes, 2018).

Posyandu Lansia merupakan wahana pelayanan bagi kaum usia lanjut, yang dilakukan dari, oleh, dan untuk kaum usila yang menitik beratkan pada pelayanan promotif dan preventif, tanpa mengabaikan upaya kuratif dan rehabilitatif. Apapun upaya promotif dan preventif tersebut dapat diterapkan dengan melaksanakan kegiatan posyandu Lansia dan menerapkan pola hidup sehat serta berperan aktif dalam gerakan kesehatan di usia lanjut dengan tujuan untuk mewujudkan masa tua yang berbahagia dan berguna (Martono, 2018).

Faktor yang menyebabkan Lansia untuk mengikuti Posyandu Lansia adalah kemampuan Lansia menggunakan pelayanan kesehatan yang diperkirakan berdasarkan faktor pendidikan, pengetahuan, sikap Lansia, jarak Posyandu. (Anonim, 2010).

Setelah dilakukan survey awal terhadap jumlah usia lanjut di beberapa wilayah kerja puskesmas pembantu yang ada disekitar daerah Bangkinang, didapatkan Puskesmas pembantu Desa Salo Timur memiliki jumlah Lansia yang paling sedikit yang aktif di Posyandu Lansia. Diantaranya yaitu Posyandu Lansia Desa Siabu memilki 75 orang Lansia yang aktif dari 115 orang Lansia. Di Posyandu Lansia Desa Kumantan terdapat 90 orang Lansia yang aktif dari 205 orang Lansia.

Sedangkan di Desa Salo Timur terdapat 328 jiwa Lansia, namun hanya 30 orang yang aktif untuk mengikuti kegiatan posyandu Lansia. Karena Lansia memandang posyandu masih sebagai sebuah rutinitas biasa yang kalau 
dijalankan tergantung waktu luang dan tidak memberikan sebuah pengaruh yang signifikan. Berdasarkan uraian diatas dapat dilihat masih banyak usia lanjut yang belum mengikuti kegiatan posyandu Lansia. Tujuan penelitian ini untuk mengetahui tentang "Gambaran Pengetahuan dan Sikap Penyebab Rendahnya Kunjungan Lansia di Posyandu Lansia Salo Timur Tahun 2021”.

\section{METODE}

Desain Penelitian yang digunakan adalah desain penelitian deskriptif yaitu untuk mengetahui Gambaran Pengetahuan dan Sikap Penyebab Rendahnya Kunjungan Lansia di Posyandu Lansia Salo Timur Desa Salo Timur Tahun 2021 (Notoatmodjo, 2012). Penelitian dilakukan pada tanggal 13-17 Juli 2021. Populasi dalam penelitian ini adalah semua Lansia Desa Salo Timur sebanyak 298 orang. Pengumpulan data dilakukan dengan cara penyebaran angket kepada lansia berbentuk multiple choice dan skala likert. Pengolahan data dilakukan dengan cara editing, coding, entry, tabulating. Analisa data dalam penelitian ini ialah secara univariat.

\section{HASIL}

\section{Data Umum}

Tabel 1. Distribusi Frekuensi Responden Berdasarkan Jenis Kelamin Lanjut Usia di Desa Salo Timur Tahun 2021

\begin{tabular}{ccc}
\hline $\begin{array}{c}\text { Jenis } \\
\text { Kelamin }\end{array}$ & Frekuensi & Persentase \\
\hline Laki-laki & 23 orang & 29,9 \\
Perempuan & 54 orang & 70,1 \\
\hline Total & 77 orang & 100 \\
\hline
\end{tabular}

Pada tabel 1 diatas dapat dilihat bahwa sebagian besar lanjut usia berjenis kelamin perempuan sebanyak 54 orang $(70,1 \%)$, dan 23 orang $(29,9 \%)$ lanjut usia berjenis kelamin laki-laki.

Pada tabel 2 dapat dilihat bahwa sebanyak 75 orang $(97,4 \%)$ lanjut usia mempunyai tingkat pendidikan tidak tamat $\mathrm{SD}$, dan sebanyak 2 orang $(2,6 \%)$ lanjut usia mempunyai tingkat pendidikan tamat SD.

Tabel 2. Distribusi Frekuensi Responden Berdasarkan Tingkat Pendidikan Lanjut Usia di Desa Salo Timur Tahun 2021

\begin{tabular}{ccc}
\hline Pendidikan & Frekuensi & Persentase \\
\hline Tidak tamat & 75 orang & 97,4 \\
SD & 2 orang & 2,6 \\
Tamat SD & & 100 \\
\hline Total & 77 orang & 10 \\
\hline
\end{tabular}

Pada tabel 2 di atas dapat dilihat bahwa sebanyak 75 orang $(97,4 \%)$ lanjut usia mempunyai tingkat pendidikan tidak tamat $\mathrm{SD}$, dan sebanyak 2 orang $(2,6 \%)$ lanjut usia mempunyai tingkat pendidikan tamat SD.

Responden dalam penelitian ini $(97,4 \%)$ berpendidikan kurang atau tidak tamat SD.

Tabel 3. Distribusi frekuensi Responden berdasarkan Tingkat Pengetahuan Lanjut Usia di Desa Salo Timur Tahun 2021

\begin{tabular}{ccc}
\hline Pengetahuan & Frekuensi & Persentase \\
\hline Baik & 2 orang & 2,6 \\
Cukup & 12 orang & 15,6 \\
Kurang & 63 orang & 81,8 \\
\hline Total & 77 orang & 100 \\
\hline
\end{tabular}

Pada tabel 3 setelah dilakukan pengelompokan tingkat pengetahuan lanjut usia maka didapatkan hasil bahwa sebagian besar lanjut usia mempunyai tingkat pengetahuan kurang yaitu sebanyak 63 orang $(81,8 \%)$, lanjut usia yang mempunyai tingkat pengetahuan tinggi sebanyak 2 orang $(2,6 \%)$, dan selebihnya mempunyai tingkat pengetahuan sedang yaitu sebanyak 12 orang $(15,6 \%)$. 
Tabel 4. Distribusi frekuensi Berdasarkan Sikap Responden Lanjut Usia di Desa Salo Timur Tahun 2021

\begin{tabular}{crc}
\hline Sikap & Frekuensi & Persentase \\
\hline Positif & 32 orang & 41,6 \\
Negatif & 45 orang & 58,4 \\
\hline Total & 77 orang & 100 \\
\hline
\end{tabular}

Pada tabel 4 dapat dilihat sebagian besar responden mempunyai sikap Negatif terhadap Posyandu Lansia yaitu dengan persentase $58,4 \%$.

\section{PEMBAHASAN}

\section{Jenis kelamin}

Responden dalam penelitian ini sebagian besar $(70,1 \%)$ berjenis kelamin perempuan. Jumlah usia lanjut perempuan selalu akan lebih besar dibanding jumlah usia lanjut laki-laki karena usia harapan hidup kaum perempuan umumnya lebih tinggi dibanding laki-laki. Berarti hampir di semua daerah umumnya jumlah janda perempuan akan lebih banyak dibandingkan jumlah duda yang ada (Haryono, 2008).

Panjangnya angka harapan hidup penduduk usia lanjut perempuan, berhubungan dengan pengaruh hormonal pada wanita usia reproduktif. Hormon Estrogen mempunyai peranan sebagai pelindung, yang menyebabkan angka harapan hidup waktu lahir untuk perempuan lebih tinggi daripada laki-laki. Namun pada laki-laki peranan Estrogen sangat sedikit dan juga laki-laki juga mempunyai beban kerja fisik yang lebih berat, selain perilaku merokok dan kebiasaan makan yang kurang berimbang (Ismayadi, 2008).

\section{Tingkat pendidikan}

Untuk meningkatkan pembangunan suatu bangsa diperlukan kesadaran penduduk dibidang pendidikan. Hal ini membutuhkan adanya persentase penduduk dengan tingkat pendidikan yang memadai untuk mendukung pembangunan ekonomi dan sosial yang cepat.

Banyak penduduk Lansia memiliki tingkat pendidikan yang rendah, hal ini disebabkan oleh sekolah pada tahun 1950an adalah hal yang mewah. Hanya para orang kaya, priyayi, bangsawan yang memiliki posisi yang tinggi di pemerintahan yang dapat memanfaatkan fasilitas pendidikan tersebut (Erna, 2000).

\section{Pengetahuan Lansia}

Pada penelitian ini $81,8 \%$ responden memiliki pengetahuan yang kurang terhadap Posyandu Lansia. Sebagian besar pengetahuan manusia diperoleh melalui mata dan telinga. Pengetahuan yang dicakup didalam kognitif mempunyai 6 tingkatan yaitu tahu, memahami, aplikasi, analisis, sintesis dan evaluasi. Apabila tingkat pengetahuan sudah mencapai tahap evaluasi maka seseorang telah memiliki kemampuan untuk melakukan justifikasi atau penilaian terhadap suatu materi atau objek (Notoatmodjo, 2003).

Mengingat kebutuhan pelayanan kesehatan merupakan masalah utama bagi para usia lanjut, pemerintah bekerjasama dengan masyarakat telah berupaya menambah fasilitas kesehatan yaitu dengan dibukanya Posyandu lansia. Pelaksanaan Posyandu lansia diharapkan dapat menjalankan fungsinya sebagai unit terdepan dalam melakukan pembinaan dan pelayanan kesehatan kepada usia lanjut yang meliputi pemeriksaan kesehatan fisik dan mental emosional.

Kartu Menuju Sehat (KMS) usia lanjut sebagai alat pencatat dan pemantau untuk mengetahui lebih awal penyakit yang diderita atau ancaman masalah kesehatan yang dihadapi dan mencatat perkembangannya dalam buku Pedoman Pemeliharaan Kesehatan (BPPK) usia lanjut atau catatan kondisi kesehatan. (Hermiyanti, 2005).

Pengetahuan lansia akan manfaat posyandu ini dapat diperoleh dari pengalaman pribadi dalam kehidupan 
sehari-harinya. Dengan menghadiri kegiatan posyandu, lansia akan mendapatkan penyuluhan tentang bagaimana cara hidup sehat dengan segala keterbatasan atau masalah kesehatan yang melekat pada mereka. Dengan pengalaman ini, pengetahuan lansia menjadi meningkat, yang menjadi dasar pembentukan sikap dan dapat mendorong minat atau motivasi mereka untuk selalu mengikuti kegiatan posyandu lansia (Erfandi, 2009).

Oleh sebab itu pengetahuan mengenai keberadaan dan fungsi Posyandu lansia, sangat baik ditingkatkan. Karena banyak, masyarakat beranggapan bahwa keberadaan Posyandu lansia merupakan sarana pengobatan. Pada hal lebih dari itu, Posyandu lansia sangat berperan untuk mengetahui perkembangan kesehatan yang dialami seorang lansia. Sebab dengan pengetahuan dapat memberikan dorongan bagi seseorang untuk mengikuti suatu kegiatan (Anonim, 2008).

\section{Sikap Lansia}

Berdasarkan hasil penelitian sebanyak 45 orang $(58,4 \%)$ responden bersikap negatif, ini disebabkan kurangnya pengetahuan, informasi, dan pendidikan. Sesuai menurut Green (1980) dalam buku (Notoadmodjo, 2003) menerangkan bahwa sikap dipengaruhi oleh faktor predisposisi yang mencangkup pengetahuan dan sikap masyarakat tentang kesehatan, tradisi dan kepercayaan terhadap hal-hal yang berkaitan dengan kesehatan.

Ada tiga faktor yang menunjang untuk membentuk sikap yaitu : Kognitif, konatif dan afektif yang merupakan predisposisi terhadap tindakan dan perilaku seseorang.

Aspek kognitif adalah refresentasi dari apa yang dipercayai individu yang dipercayai individu yang memiliki sikap mengenai apa yang berlaku dan benar bagi objek sikap. Aspek kognitif meliputi pengetahuan, pendidikan yang saling menunjang sikap individu terhadap objek faktor pengetahuan atau faktor kepercayaan usia lanjut. Terhadap kegiatan posyandu adalah apa saja yang dipercayai usia lanjut mengenai kegiatan posyandu lanjut usia meliputi tujuan, manfaat dan frekuensi kunjungan. Aspek afektif adalah perasaan individu terhadap objek sikap yang menyangkut masalah emosional.

Aspek afektif lanjut usia terhadap kegiatan posyandu lanjut usia merupakan perasaan yang dimiliki usia lanjut terhadap kegiatan posyandu yang meliputi, merasa pentingnya mengikuti kegiatan posyandu lansia, perasaan-perasaan malu mengikuti kegiatan posyandu lansia, perasaan senang tidak senang mengikuti kegiatan posyandu lansia, perasaan malu mengikuti kegiatan posyandu lansia. Aspek ini memiliki kecenderungan dalam bertindak atau aspek kognitif merupakan kecenderungan berprilaku tertentu sesuai sikap yang dimiliki oleh seseorang untuk bereaksi terhadap sesuatu dengan cara-cara tertentu. Kecenderungan lanjut usia dalam bertindak terhadap kegiatan posyandu lansia menunjukan bagaimana perilaku atau kecenderungan perilaku yang ada dalam diri usia lanjut tersebut untuk berpartisipasi dalam kegiatan posyandu lansia. Interaksi dari kegiatan ketiga faktor sikap diatas akan selaras dan konsisten sehingga membentuk sikap yang utuh (Azwar, 2005).

Penilaian pribadi atau sikap yang positif terhadap posyandu Lansia merupakan dasar atas kesiapan atau kesediaan lansia untuk mengikuti kegiatan posyandu. Sikap lansia yang baik cenderung untuk selalu hadir atau mengikuti kegiatan yang diadakan di posyandu lansia. Hal ini dapat dipahami karena sikap seseorang adalah suatu cermin kesiapan untuk bereaksi terhadap suatu obyek. Kesiapan merupakan kecenderungan potensial untuk bereaksi dengan cara-cara tertentu apabila individu dihadapkan pada stimulus yang menghendaki adanya suatu respons (Erfandi, 2009). 


\section{KESIMPULAN}

Berdasarkan hasil penelitian yang telah dilakukan di Posyandu Lansia Desa Salo Timur, maka peneliti dapat mengambil kesimpulan sebagai berikut : Kebanyakan responden memiliki pengetahuan dengan kategori kurang $(81,8 \%)$ dan 45 orang $(58,4 \%)$ bersikap negatif terhadap posyandu lansia.

\section{UCAPAN TERIMAKASIH}

Dalam penelitian ini, peneliti banyak mendapatkan bantuan dari berbagai pihak. Sehubungan dengan hal tersebut peneliti mengucapkan terimakasih kepada Kepala Puskesmas Salo, Kepala Desa Salo Timur dan Bidan desa yang berada di Posyandu Salo Timur, serta Ketua LPPM Universitas Pahlawan Tuanku Tambusai.

\section{DAFTAR PUSTAKA}

Anderson, E. (2007). Buku Ajar Keperawatan Komunitas. Edisi 3. Jakarta. EGC.

Anonim. (2001). Di Jemberana Posyandu Tak Lagi Sekedar Pos Kesehatan. http://www.seputar kita.go.id. .(2008). Peran Kader Posyandu di Desa Bletok. http://www.republika.go.id . Diperoleh tanggal 8 Juli 2021

Beare, Patricia. (2007). Buku Ajar Keperawatan Gerontik. Edisi 2. Jakarta: EGC.

Darmajo, B. (2006). Buku Ajar Ilmu Kesehatan Usia Lanjut. Edisi ke 3. Jakarta: EGC.

Departemen Kesehatan RI. (2007). Pedoman Petugas
Posyandu Lansia. Jakarta: DEPKES RI.

Dinas Kesehatan. (2006) Profil Dinas Kesehatan Kabupaten Kampar: Bangkinang.

Erfandi. (2009). Pengelolaan Posyandu

Lansia . Jakarta

Erna. (2000). Gerakan Nasional Pemberdayaan Lanjut Usia.

http://www.republika.go.id

Hermayanti, Sri. (2005). Di Jember Posyandu Tak Lagi Sekedar Pos Kesehatan. http://www.seputar kita.go.id.

Hidayat, A. A (2007). Riset Keperawatan \& teknik Penulisan Ilmiah. Edisi 2. Jakarta: Salemba Medika.

Irfan. (2007). Pengetahuan Pelayanan Fisik Usia Lanjut. http://www.pjnk.go.id.

Diperoleh tanggal 14 Juli 2021

Ismayadi. (2008). Masa Tua yang Sejahtera.

http://www.Depkes.co.id. Diperoleh tanggal 7 Juli 2021

Machfoedz, Irham. (2006). Statistik Diskriptif Cetakan ke-IV. Yogyakarta. Fitramaya Martono. (2000). Geriatrik. Jakarta: FKUI Notoatmodjo, S. (2003). Buku Ajar Ilmu Kesehatan Masyarakat. Jakarta: EGC. (2005). Metodologi Penelitian Kesehatan. Jakarta: EGC. 
(2007). Buku Ajar Ilmu Kesehatan Masyarakat. Jakarta: EGC.

Nugroho, W. (2000). Keperawatan Gerontik. Edisi 2. Jakarta: EGC.

Nursalam. (2003). Konsep \& Penerapan Metodologi Penelitian
Ilmu Kesehatan. Jakarta: Salemba Medika.

Syamsudin. (2001). Gerakan Nasional Pemberdayaan Lanjut Usia.

http://www.republika.go.id 